\title{
Water Quality Criteria for Water Bodies in Urban Areas and Accompanying Changes in Surrounding and In-Situ Vegetation: Considerations from the Landscape Aspect of Planning Water Recreational Areas
}

\author{
Shigeki Harada ${ }^{1}$, Risa Wagatsuma ${ }^{2}$, Tatsunari Koseki ${ }^{3}$, Toshiaki Aoki ${ }^{1}$, Taisuke Hashimoto ${ }^{1}$ \\ ${ }^{1}$ Department of Environmental Sciences, Miyagi University, Miyagi, Japan \\ ${ }^{2}$ JR East Urban Development, Tokyo, Japan \\ ${ }^{3}$ Kyoen, Ltd., Miyagi, Japan \\ Email: "haradas@myu.ac.jp
}

Received November 7, 2012; revised December 13, 2012; accepted December 26, 2012

\begin{abstract}
Water bodies in urban areas are important as recreational areas. Thus, management plans that maintain high water quality are quite important. At the Hatadate Water Park adjacent to Miyagi University, water quality parameters such as visibility, COD, TOC, and TN were monitored at a small pond and the inflowing stream from August to December in 2011, and photographs were taken of these sites. Variations in COD and TOC were highly related to changes in the physical appearance, especially changes in vegetation. These findings suggest: 1) the importance of management of vegetation for water quality control; and 2) the importance of collecting photographic records of sites for research purposes of interpreting data and even as a data point of water quality. Together with the water quality goals for water bodies in urban areas proposed by Sudo et al. [1], these water quality criteria were assessed, and it was notable that COD often exceeded the set goal. These results suggest that the maintenance of vegetation is more important than controlling incoming TN for primary production in the pond. Seasonal variations in COD and TOC were plotted for surface water of Kamafusa and Okura dams, both are important lakes in Miyagi area and the catchments of both lakes are mainly hilly area, using published water quality reports. Similar annual-cycle changing patterns were shown both for the dams, implying that some kinds of ecological factors in the catchments are affecting the water qualities of the dam, even at those larger scale water bodies. Finally, by shifting the focus from only water to upstream features such as small park, or pocket park, with a parking lot for the water body, the importance of landscape including vegetation and tree cover was highlighted.
\end{abstract}

Keywords: Small Water Body; COD; TOC; Vegetation; Landscape

\section{Introduction}

The recreational function of water bodies has been gaining increased attention [2]. This is especially important in urbanized area, where small reservoirs, ponds, streams, and rivers provide opportunities for contact with aquatic environments and for recreation. In Japan, a five-axis comprehensive evaluation system for urban water bodies has recently been developed [3]: 1) how natural the area is; 2) how abundant the biomass (and vegetation) in the area is; 3) how clean the water in the area is; 4) how comfortable the area is; and 5) how close the interactions with human activities in the surrounding region are.

\footnotetext{
"Corresponding author.
}

Of these, the authors selected 2) and 3) for analysis and focused on the vegetation (or ecosystem) around the water body, water quality, and the surrounding landscape, which includes vegetation and the ecosystem of surrounding areas. Concerning the effects of landscape on water bodies, a recent paper [4] considered that water quantity is highly affected by the landscape of the catchment. We also expect that water quality is affected by landscape.

In this paper, the main purpose is to analyze the possible relationship between water quality and changes in the surrounding and in-situ landscapes through photographs. We make our analysis on a small scale. We focus on the physical appearance of the water body and the surround- 
ing areas. There are two merits to this kind of approach: 1) generating a larger research record as the photographs show the physical conditions of the places at the time that monitoring was done; and 2) have implications for landscape planning, especially with regard to how the ecosystems (mainly vegetation) should be maintained.

We demonstrate the close relationship between water quality and landscape. Further, we summarize the results of the satisfaction ratio and analyses of the water quality of water bodies in urban areas as proposed by Sudo et al. [1]. Finally, suggestions for improvements of the are from the viewpoint of landscape planning around a pocket park are given.

\section{Materials and Methods}

\subsection{Study Site}

Hatadate Water Park (total area, 0.9255 ha) has five ponds and the main vegetation in the surrounding areas is red pine. The five ponds are accessible by car or on foot from Taihaku campus of Miyagi University (5 min or 30 min, respectively), and local residents utilize the park for taking walks.

\subsection{Sampling}

Sampling was conducted in Naka Pond (Figure 2), which has adjoining parking lots and a nearby walkway, and at the inflow stream (Figure 1), every two weeks from August to December 2011. Water was collected by acid-cleaned polyethylene bucket. At the inflow stream, we waded into the water, keeping the disturbance to a minimum, and sampled the surface water. To sample the pond, we threw the bucket with a rope from the concrete embankment and collected surface water. Water temperature and visibility were recorded using the sampled water, and water samples were transported to the laboratory in 1-L acid-cleaned polyethylene bottles. Photographs were taken from fixed points at each site.

\subsection{Analyses}

Samples for COD determination were digested at $100^{\circ} \mathrm{C}$ for 30 minutes by DRB200 (Hack). Digested water samples were injected into pre-prepared ampules containing reagents (oxidation by $\mathrm{KMnO}_{4}$ ) based on the JIS K0102 method. Measurement was done by UV-Vis spectrophotometer DR-5000 (Hack) [5]. Compared to the full wet chemistry of the JIS K0102 method, the slope of the correlated line was nearly 1 and $r=0.97$ in the range 0.5 to $12 \mathrm{mg} / \mathrm{L}$.

TOC was determined using the NPOC method [6,7]; that is, the sample was sparged with zero grade (hydrocarbon-free) air under $\mathrm{pH}<3$. And then combusted at the furnace and all carbon was converted to $\mathrm{CO}_{2}$ and meas- ured by NDIR.

TN was measured using the ozonation method [6,7]. NPOC and TN were measured simultaneously. Here, we shortened the time required for measurement by only conducting one measurement on each sample after confirming that the background carbon level was less than $0.01 \mathrm{mg} / \mathrm{L}$. Based on analysis of the replicate measurement for the samples taken at the same site, we confirmed that the standard error was less than 5\%.

\subsection{Factors Affecting Accuracy and Precision of the Analyses}

Background contamination and standard error for COD were monitored for replicate 5 samples (dam retained water). The background contamination was 0 . And standard error was less than 5\%. As mentioned above, observed COD values was highly correlated to that of JIS K0102 values, moreover the slope of the correlated line was nearly 1 , thus, The accuracy of this method was confirmed to be very high.

Also background contamination for TOC and TN were monitored for milli-Q water. And, standard error and accuracy for TOC and TN were monitored for replicate 5 measurements of the standard samples (TOC reagent equivalent to $5.3 \mathrm{mg} / \mathrm{L}$ and $\mathrm{TN}$ reagent equivalent to 5.1 $\mathrm{mg} / \mathrm{L})$. The background contamination for TOC and TN were $0.05-0.08 \mathrm{mg} / \mathrm{L}$ and $0.00 \mathrm{mg} / \mathrm{L}$ for TOC and TN, respectively. The average and the standard deviation of the replicate 5 measurements of TOC standard sample were $5.44 \mathrm{mg} / \mathrm{L}$ and $0.06 \mathrm{mg} / \mathrm{L}$, respectively, showing very small standard error. Considering the TOC background, the accuracy of the TOC measurement is high enough for measurement of natural level samples. The average and the standard deviation of the replicate 5 measurements of TN standard sample were $5.1 \mathrm{mg} / \mathrm{L}$ and $0.25 \mathrm{mg} / \mathrm{L}$, respectively. The accuracy of TN was very high and the standard error was just 5\%.

\subsection{Plots of the Variations in Seasonal Water Quality Trends in Two Major Dams}

Using published water quality reports [8-11], variations in COD and TOC at the surface of Kamafusa and Okura dams were plotted. Both dams are important dams in Miyagi area, and the catchments of both dams are mainly hilly area. Thus, the water quality trends are thought to imply the effects of changing ecosystems of the catchments.

\section{Results}

\subsection{Changes in Surrounding and In-Situ Visual Appearance at the Hatadate Water Park}

Time-series photographs taken at the inflow and of the 


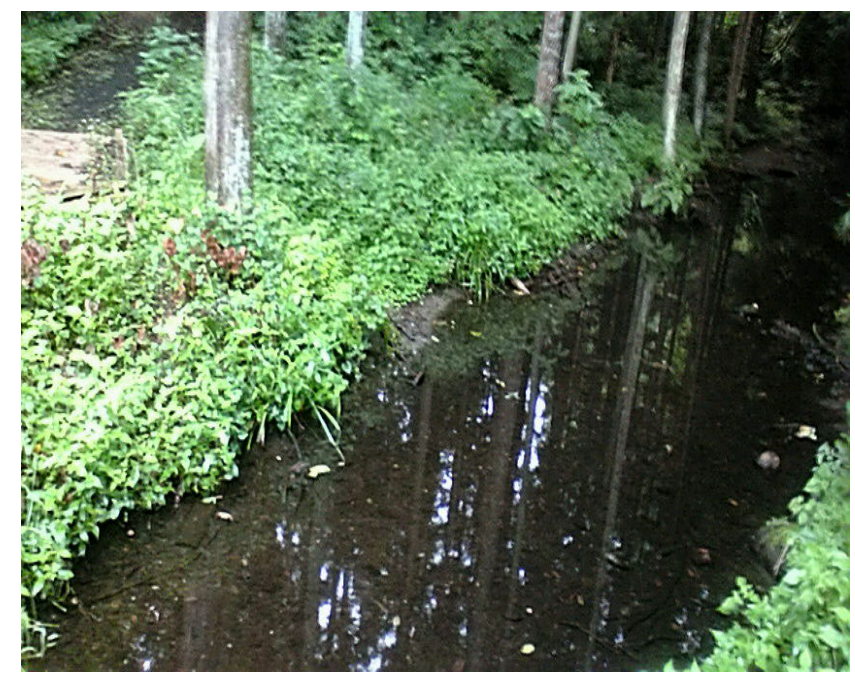

(a)

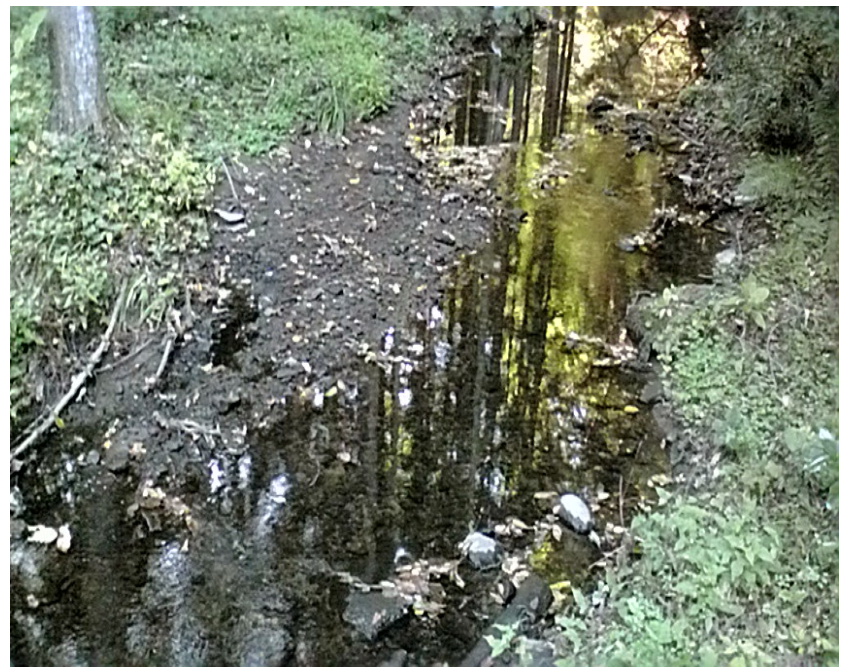

(c)

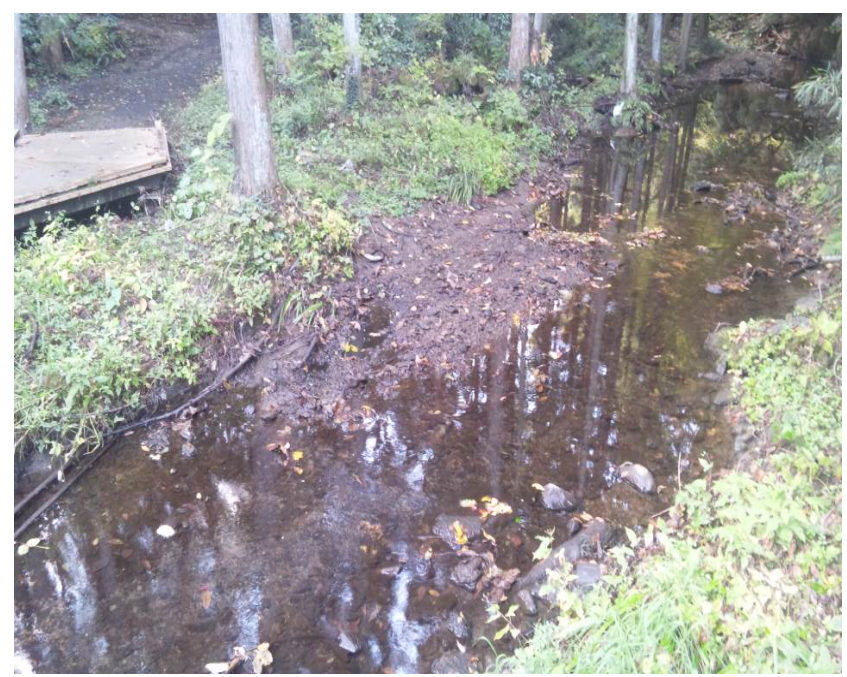

(b)

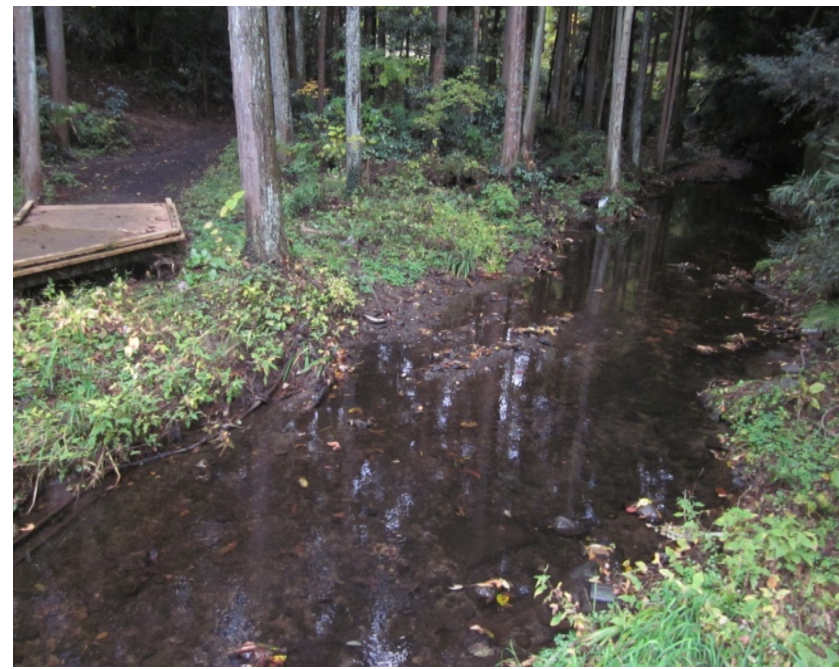

(d)

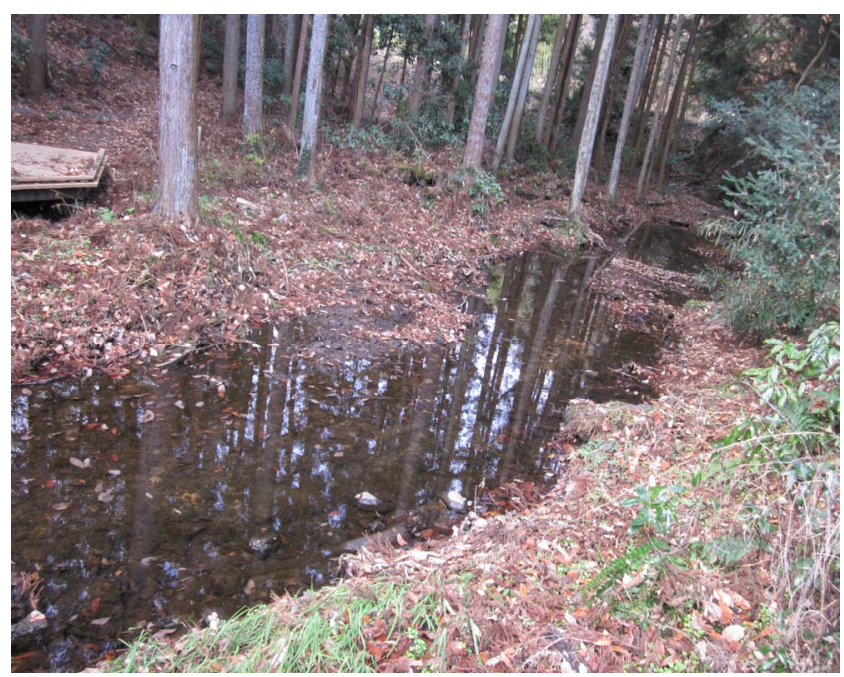

(e)

Figure 1. Photographs of the inflow stream in 2011: (a) August; (b) September; (c) October; (d) November, and (e) December. 


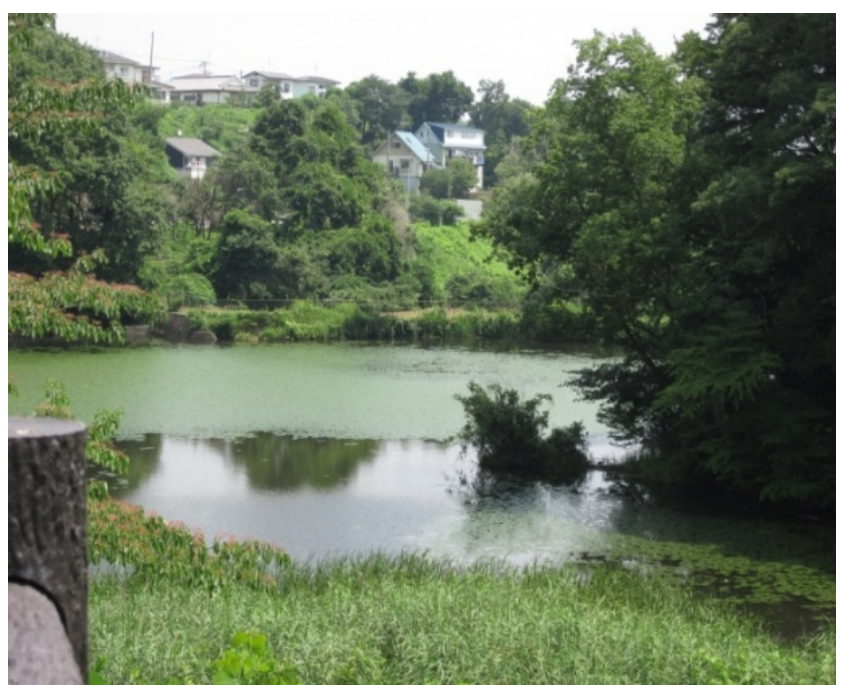

(a)

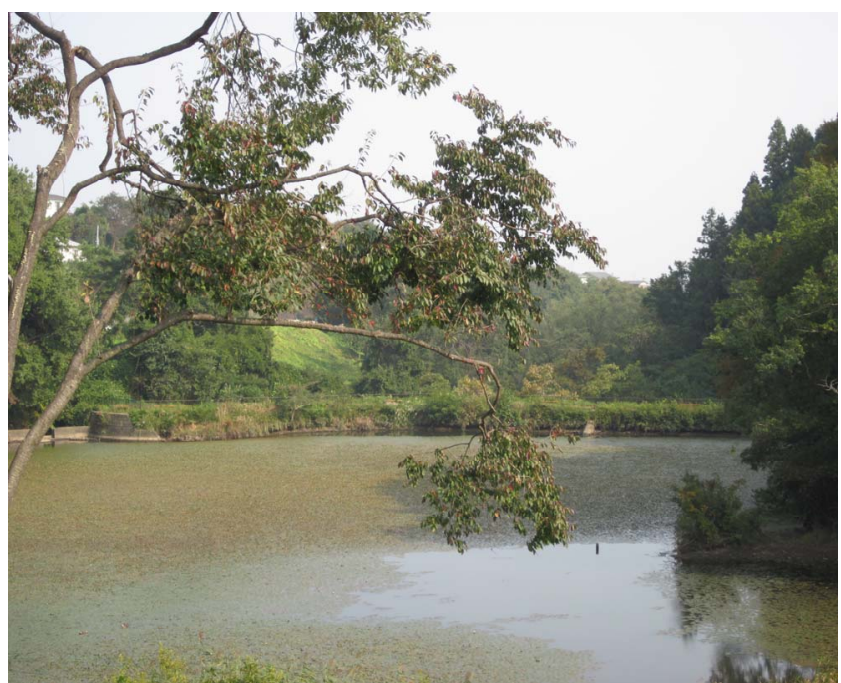

(c)

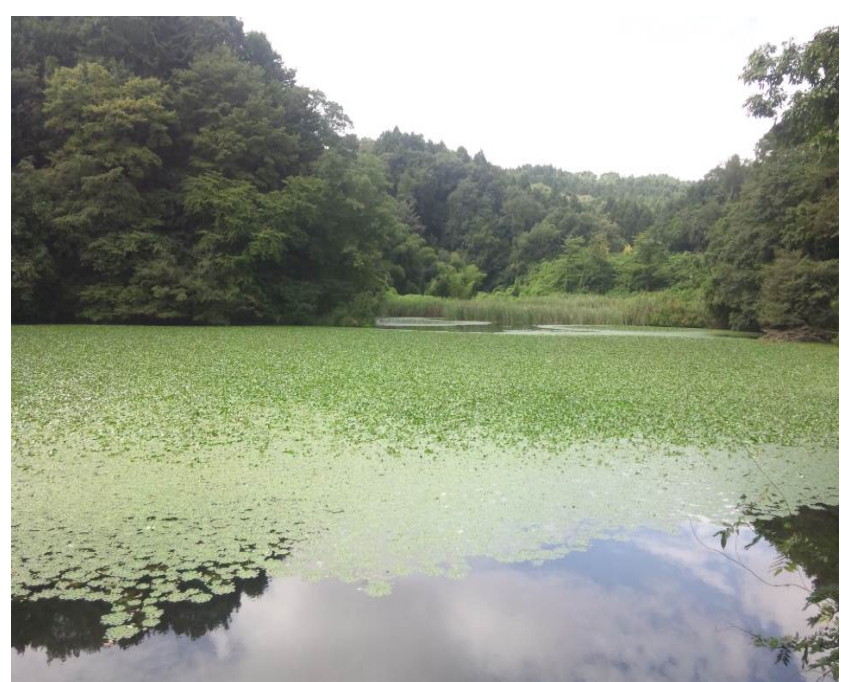

(b)

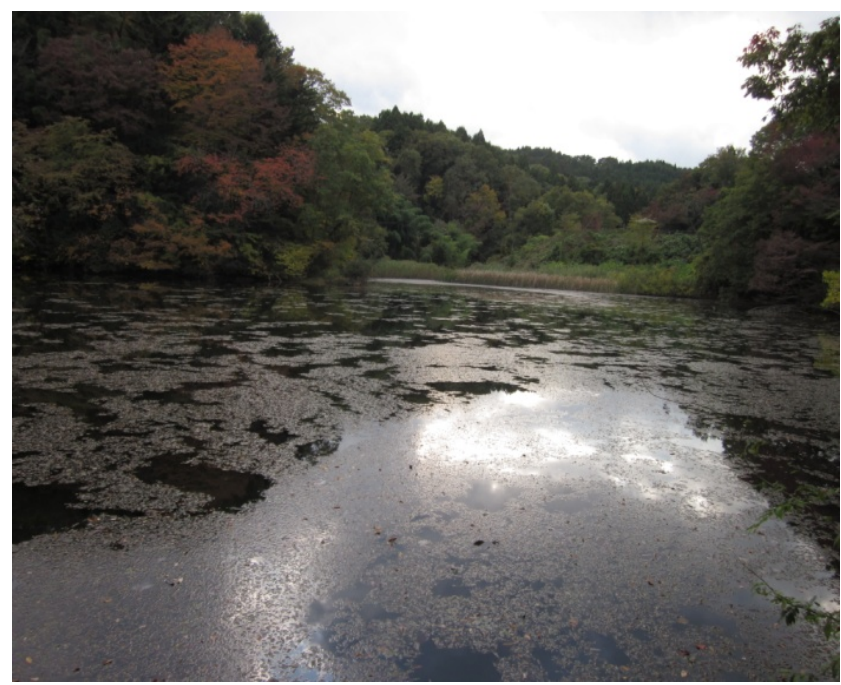

(d)

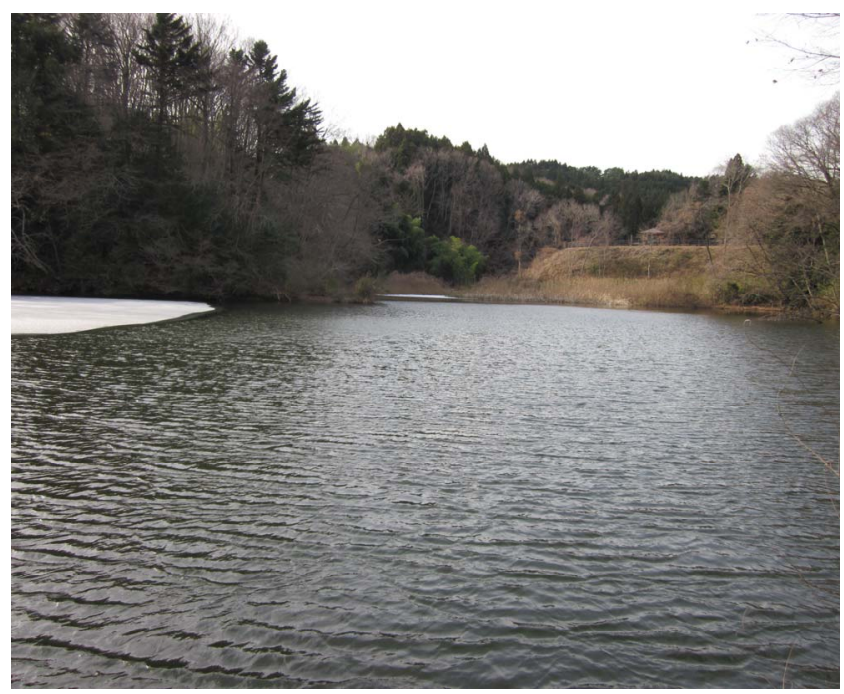

(e)

Figure 2. Photographs of the pond in 2011: (a) August; (b) September; (c) October; (d) November; and (e) December. 
pond are shown in Figures 1 and 2, respectively. The appearance of these two points changed drastically with time. Especially, the changes are clearer at the ponds.

The leaves of the trees were initially totally green (Figures 2(a) and (b) while part of them became red in fall (d) and then became dark (e). At the same time, the water grass at the surface once increased (b) and decreased (c). And then it became scam-like particles (d) and then became clear (e).

\subsection{Changes in Water Quality at the Hatadate Water Park}

Visibility was always over $50 \mathrm{~cm}$ both at the inflow and in the pond. The other parameters are shown in Figures 3-5. TN at the inflow was always higher than that in the pond, indicating the effects of input from a small field and rice field.

We observed the existence of some fields and rice fields by means of our own exploration of the catchment of the study site though the map shows major land use of the catchment is forest. COD both at the inflow and in the pond were high even though visibility was high. TOC and COD seemed not to be coincidental (Figures $\mathbf{4}$ and 5). However, discrete statistical analyses (correlation analyses) showed a strong, positive relationship between them [6]. The sharp increases in COD and TOC at November 7

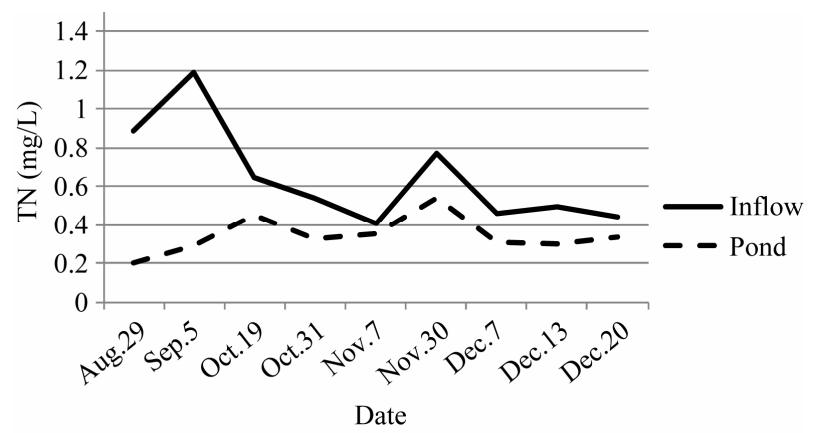

Figure 3. TN at the inflow and in the pond from August to December 2011.

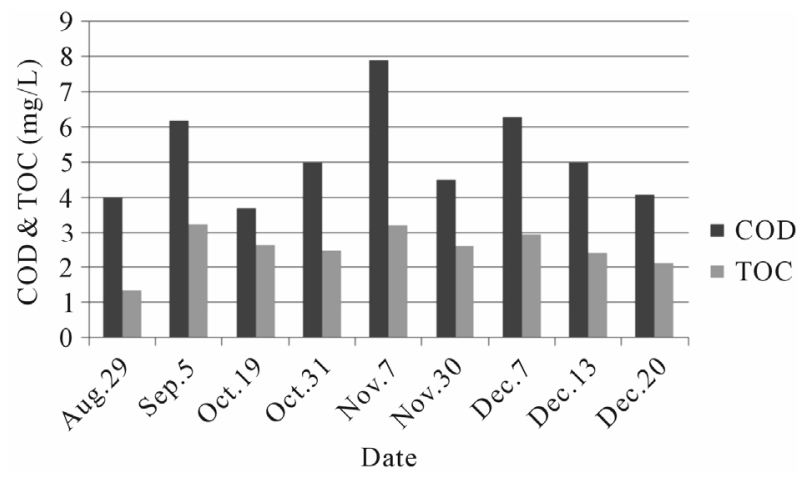

Figure 4. COD and TOC at the inflow from August to December 2011.

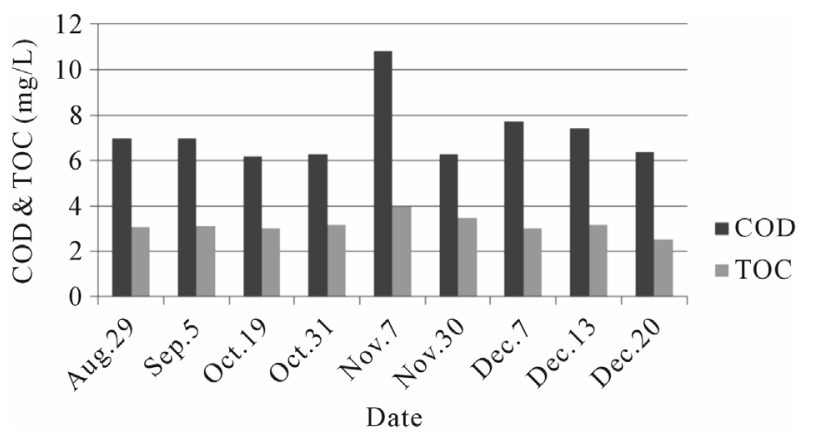

Figure 5. COD and TOC in the pond from August to December 2011.

were observed both at the inflow and in the pond, and the increase was bigger for the sampling point in the pond.

\subsection{Variations in the Surface Water Qualities at the Kamafusa and Okura Dams}

At Kamafusa (Figure 6) and Okura (Figure 7) dams, COD and TOC showed similar annual-cycle changing trends for 4 years. Of these, trends in 2 years for both dams were shown. Because the catchments of both Kamafusa and Okura dams are hilly (forest) areas, the major factor affecting the variations are thought to be changes in ecosystems. This finding is interesting because the seasonal changes in water qualities could be seen in larger water bodies.

\section{Discussion}

The percentage of time points at which the water quality parameters are within the criteria described in Table 1 may serve as an indicator of the success of water management of small water bodies such as the ones we monitored here (Table 2).

The goals (Table 1) were modified considering the likely pollution sources of the water bodies and the measurement capabilities of our laboratory.

Separately, a comprehensive review of water quality control and measurement method has been prepared by the authors [7]. This review may be helpful to understand ongoing aquatic environment management policy in Japan (e.g., $\mathrm{Mn}$ is monitored instead of $\mathrm{Cr}$ as an oxidizer).

All visibility data points satisfied the criteria. A visibility value over $50 \mathrm{~cm}$ suggests that the water is fairly clean [12]. A $100-\mathrm{cm}$ visibility meter is available and would be more appropriate for measurement considering the water quality encountered at our site. These results suggest that water quality parameters can fail the criteria even when visibility is high.

For the parameter COD, the criteria was satisfied at a rate of $66.7 \%$ at the inflow and $0 \%$ at the pond. These results indicate that water management to reach the level of the Lake Environmental Standard is quite difficult for 


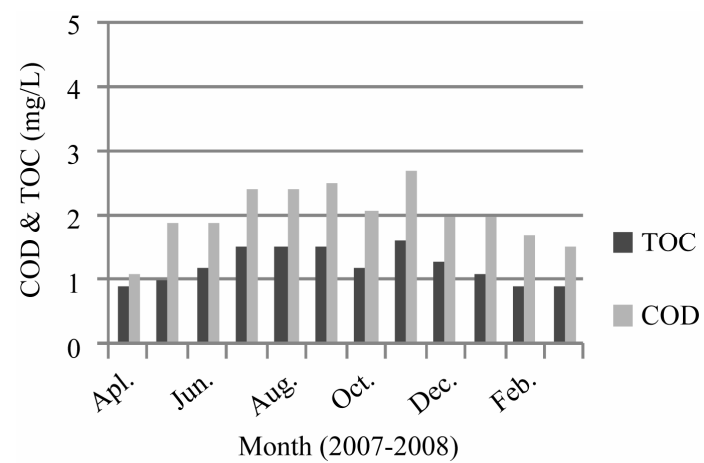

(a)

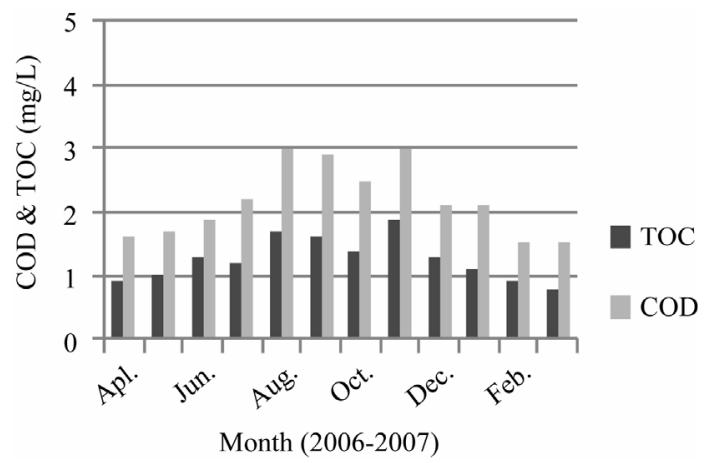

(b)

Figure 6. Monthly COD and TOC at the surface of Kamafusa dam; (a) 2007-2008; (b) 2006-2007.

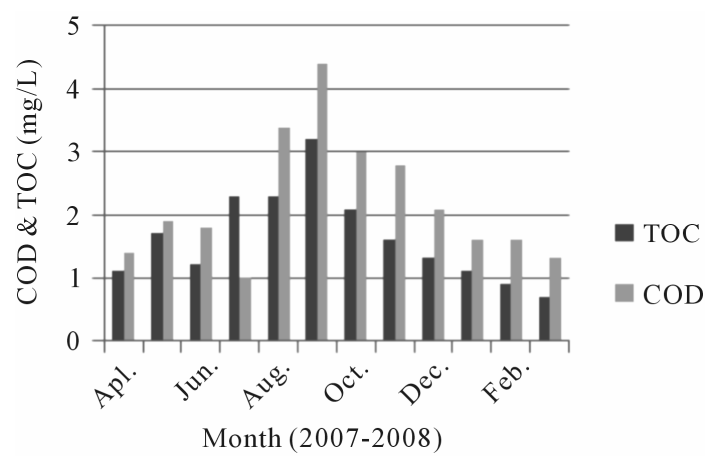

(a)

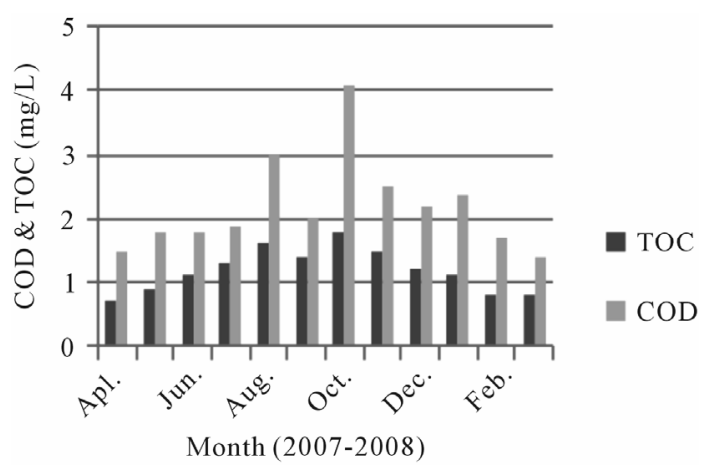

(b)

Figure 7. Monthly COD and TOC at the surface of Okura dam; (a) 2007-2008; (b) 2006-2007.
Table 1. Water quality criteria and goals for water bodies in urban areas (After Sudo et al. 2008 [1]).

\begin{tabular}{cc}
\hline Indices & Goal \\
\hline SS & $10 \mathrm{mg} / \mathrm{L}$ \\
Transparency & $1 \mathrm{~m}$ \\
Visibility & $50 \mathrm{~cm}$ \\
BOD & $3.0 \mathrm{mg} / \mathrm{L}$ \\
COD & $5.0 \mathrm{mg} / \mathrm{L}$ \\
TN & $1.0 \mathrm{mg} / \mathrm{L}$ \\
TP & $0.1 \mathrm{mg} / \mathrm{L}$ \\
\hline
\end{tabular}

Table 2. Success of meeting selected water quality criteria goals from Table 1 for the pond and inflow sampling points.

\begin{tabular}{ccc}
\hline Indices & Inflow & Pond \\
\hline Visibility (Range) & $50 \mathrm{~cm} \sim$ & $50 \mathrm{~cm} \sim$ \\
Visibility (Satisfaction Ratio) & $100 \%$ & $100 \%$ \\
COD (Range) & $3.2-7.9 \mathrm{mg} / \mathrm{L}$ & $6.2-10.8 \mathrm{mg} / \mathrm{L}$ \\
COD (Satisfaction Ratio) & $66.7 \%$ & $0 \%$ \\
TN (Range) & $0.4-1.2 \mathrm{mg} / \mathrm{L}$ & $0.2-0.55 \mathrm{mg} / \mathrm{L}$ \\
TN (Satisfaction Ratio) & $89.0 \%$ & $100 \%$ \\
\hline
\end{tabular}

Each $\mathrm{N}=9$.

standing water bodies. Concerning TN, the goal (less than $1.0 \mathrm{mg} / \mathrm{L}$ ) was exceeded only at one time point on 5 September. Presumably, this peak was due to runoff from farmland areas around the inflow stream. Further monitoring, such as the monitoring during rainfall events, is needed.

COD was very high, especially in the pond. The increase at Nov. 7 is corroborated by an increase in TOC. The possible reasons for this big increase are: 1) inflow of COD via inflow stream; 2) biological production affected by $\mathrm{TN}$; and 3) decomposition of biological substances within the pond. First, we reject 1) because inflow COD is smaller than that of pond. Also we rejected 2) because there was higher TN on November 30, despite smaller COD and TOC values. Moreover, the amount of TN supplied through the inflow might be small. As shown in Figure 1 and in our observations, the inflow rates were very small. Thus, the mechanism is expected to be 3). As shown in Figure 2(d) (taken November 7), the water grass at the surface of the pond quickly decreased and flocks of bio-source matter could be seen. In our sampling, the water was colored, despite the high visibility value. These results underline the relationship between water and vegetation.

Because of the strong correlation between COD and 
TOC [6], possible reasons for the sudden increase of COD at November 7 could be discussed based on prepublished information about TOC and/or DOC increase within aquatic environments. The possible reasons could be picked up by rather comprehensive review of aquatic organic material cycles:

- Increased photosynthesis and resulting increase in phytoplankton extracellular leakage of produced organic materials [13];

- Sloppy feeding of zooplankton on their grazing of phytoplankton [14,15];

- Excretion of zooplankton [16];

- Rapid particle dissolution during sinking [17-19].

Of these, the last phenomena [17-19] could be rejected because the sudden increase at November 7 was occurred at the surface. The first phenomena, often, might be picked up as a possible increase of TOC and/or DOC at the surface, however, considering that the timing was fall, high primary production rate is not realistic. Thus, the extracellular leakage of photosynthetic materials, also, could be rejected as the reason for the sudden increase.

The remaining two phenomenon are also zooplankton origin mechanisms. Copping and Lorenzen (1980) [14] and Lampert (1978) [15], separately, insists that more than $10 \%$ of grazing organic carbon could be increase of DOC in water. Moreover, Eppley et al. (1981) [16] estimates that zooplankton excretion the rate of which is less than that of $10 \%$ of primary production could be increase of DOC in water. These phenomenon absolutely would be important mechanisms concerning organic material cycles within aquatic ecosystems, however, they could not be the major reasons for the sudden increase, because similar increase could not be seen during the other periods.

Thus, the authors conclude that the sudden increase was occurred by decomposition of the water grass of the surface as seen in the photo picture. At the larger water bodies, such as Kamafusa and Okura dams, also large increase in COD and/or TOC could be seen in both of the monthly plots for four years. However, because of the lack of detailed information about ecosystems in the two catchments, we could not specify the reasons of the increase. At least, we could say that the water qualities show repetitive changes, and it is natural to associate these changes with ecological conditions in the catchments. Further analyses are needed to get detailed information.

\section{Planning Aspect of Urban Water Body Management}

The pond surface is 30 to $40 \mathrm{~m}$ lower than that of the parking lots shown in the Figure 8. For residents in the area, the parking lots and shelter are important places for recreation.

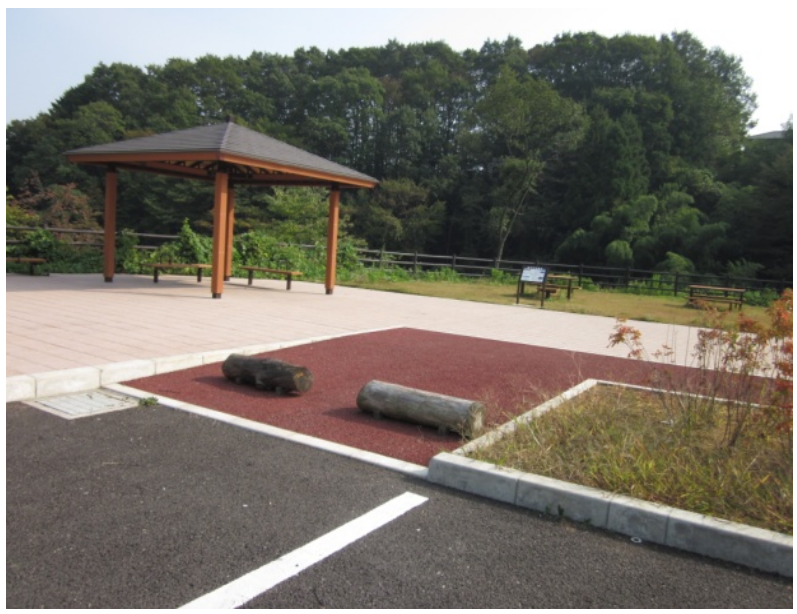

Figure 8. View of shelter and parking areas located upstream of Naka Pond at Hatadate Water Park.

The place is neat and calm. While people rest in the park area, they can look down on the water and enjoy the beautiful vegetation. The question is what is the most important feature for people when they visit this place. From a landscape aspect point-of-view, the vegetation shown in Figure 2 may soothe people from their vantage point in the parking lot. However, vegetation cover results in the deterioration of water quality. Further analyses, including a questionnaire, are needed to design landscapes that are conducive for both human recreation and water quality.

\section{Acknowledgements}

This research was conducted with support from the Miyagi University Research Fund.

\section{REFERENCES}

[1] Japan Society for Water Environment, "Integrated Index of Water Environment Quality,” 2004.

[2] J. T. Hamad, T. A. Eshtawi, A. M. Abushaban and M. O. Habboub, "Modeling the Impact of Land-Use Change on Water Budget of Gaza Strip,” Journal of Water Resource and Protection, Vol. 4, 2012, pp. 325-333. doi:10.4236/jwarp.2012.46036

[3] R. Sudo, O. Nishimura, N. Chiba and S. Harada, "Restoration and Creation of Waterfront in Urban Area-Goal of Water Quality and Problems of Applying Technologies,” Journal of Hydrological Systems, Vol. 67, 2008, pp. 5-13.

[4] S. Harada and Y. Mifune, "Planning of Open Space and Water Recreational Area,” In: Y. Mifune, Ed., Keyword for City Planning, Gakugei Press, 2009, pp. 195-214.

[5] S. Harada and Y. Komuro, "Decrease of Non-Point Zinc Runoff Using Porous Concrete,” Chemosphere, Vol. 78, No. 4, 2010, pp. 488-491. doi:10.1016/j.chemosphere.2009.10.010 
[6] S. Harada, R. Wagatsuma, T. Koseki, T. Aoki and T. Hashimoto, "Relationship between TOC and COD at Pond," Journal of Water and Waste, in Press.

[7] S. Harada and R. Wagatsuma, "Water Quality Indices for Management of Water Body Especially TOC and COD Measurement Methods,” Journal of Environmental Engineering and Management, in Press.

[8] Sendai City, “Annual Water Quality Report,” 2005-2006.

[9] Sendai City, “Annual Water Quality Report,” 2006-2007.

[10] Sendai City, “Annual Water Quality Report,” 2007-2008.

[11] Sendai City, “Annual Water Quality Report,” 2008-2009.

[12] K. Somiya and H. Tsuno, "Environmental Water Quality," Corona Press, 1999.

[13] S. B. Baines and M. L. Pace, "The Production of Dissolved Organic Matter by Phytoplankton and Its Importance to Bacteria: Patterns across Marine and Freshwater Systems," Limnology and Oceanography, Vol. 36, No. 6, 1991, pp. 1078-1090. doi:10.4319/lo.1991.36.6.1078

[14] A. E. Copping and C. J. Lorenzen, "Carbon Budget of Marine Phytoplankton-Herbivore System with Carbon-14 as a Tracer," Limnology and Oceanography, Vol. 25, No. 5, 1980, pp. 873-882. doi:10.4319/lo.1980.25.5.0873

[15] W. Lampert, "Release of Dissolved Organic Carbon by Grazing Zooplankton,” Limnology and Oceanography, Vol. 23, No. 4, 1978, pp. 831-834. doi:10.4319/lo.1978.23.4.0831

[16] R. W. Eppley, S. G. Horrigan, J. A. Fuhrman, E. R. Brooks, C. C. Price and K. Sellner, "Origins of Dissolved Organic Matter in Southern Calfornia Coastal Waters: Experiments on the Role of Zooplankton," Marine Ecology Progress Series, Vol. 6, 1981, pp. 149-159. doi:10.3354/meps006149

[17] B. C. Cho and F. Azam, "Major Role of Bacteria in Biogeochemical Fluxes in the Ocean's Interior," Nature, Vol. 332, No. 6163, 1988, pp. 441-443. doi:10.1038/332441a0

[18] D. M. Karl, G. A. Knauer and J. H. Martin, "Downward Flux of Particulate Organic Matter in the Ocean: A Particle Decomposition Paradox,” Nature, Vol. 332, No. 6163, 1988, pp. 438-441. doi:10.1038/332438a0

[19] D. C. Smith, A. L. Simon, A. L. Alldredge and F. Azam, "Intense Hydrolytic Enzyme Activity on Marine Aggregates and Implications for Rapid Particle Dissolution," Nature, Vol. 359, No. 6391, 1992, pp. 139-142. doi: $10.1038 / 359139 \mathrm{a} 0$ 